Published in final edited form as:

Org Lett. 2007 December 20; 9(26): 5537-5540.

\title{
Facile Synthesis of Naphthoquinone Spiroketals by Diastereoselective Oxidative [3 + 2] Cycloaddition
}

\author{
Kun-Liang Wu, Stephanie Wilkinson, Norbert O. Reich, and Thomas R. R. Pettus \\ Department of Chemistry and Biochemistry, University of California at Santa Barbara, Santa \\ Barbara, California 93106-9510
}

\section{Abstract}

A highly selective oxidative [3+2] cycloaddition of chiral enol ethers and hydroxynaphthoquinone is described. This convergent strategy is amenable to an enantioselective synthesis of $\beta$-rubromycin and related naphthoquinone spiroketals. Several compounds were found to inhibit DNA-polymerase and telomerase in a manner resembling $\alpha$-rubromycin and $\beta$-rubromycin.

$(+)-\beta$-Rubromycin belongs to a unique family of optically active spiroketal natural products with a rich and emerging history (Figure 1). ${ }^{1}$ Brockmann first isolated $\alpha$-rubromycin (1), $\beta$ rubromycin (2a), and $\gamma$-rubromycin (3) in 1966 from strains of Streptomyces collinus bacteria. ${ }^{2}$ However, Zeeck later revisited the structure in 2000 and assigned it as the $p$-quinone (2b).

3 With assistance from Bringmann, an $S$-configuration was assigned to the unique spiroketal in $\mathbf{2 b}$ using circular dichroism. ${ }^{4} \beta$-Rubromycin (2b) and $\gamma$-rubromycin (3) inhibited telomerase with an $\mathrm{IC}_{50}$ of less than $3 \mu \mathrm{M} .{ }^{1}$ On the other hand, $\alpha$-rubromycin (1) proved inactive $\left(\mathrm{IC}_{50}>\right.$ $200 \mu \mathrm{M})$, exhibiting efficacy well outside the window of the assay. ${ }^{1}$ Because of this discrepancy between $\mathbf{1}$ and $\mathbf{2}$ and $\mathbf{3}$, Hayashi proposed that the spiroketal moiety found in the structure of the inhibitors was responsible for their efficacy and as a privileged structural component offered a good starting point for synthetic chemists.

From a synthetic perspective, rubromycins ( 2 and $\mathbf{3}$ ) pose several interesting questions. ${ }^{1}$ These molecules are presumably biosynthesized as single enantiomers. However, each contains a single spiroketal stereocenter. Therefore, these compounds do not appear to be biosynthesized by a conventional thermodynamic ketalization. Nevertheless, the universal strategy has been to anneal two components together about a centralized carbonyl moiety. ${ }^{5}$ Researchers synthesized lower oxidation surrogates of the naphthoquinone moiety, such as naphthazarin and benzyloxy derivatives. Most have reported methods to anneal these fragments together. 6 Despite several extraordinary efforts, only Danishefsky and co-workers reported synthesizing a naphthoquinone-isocoumarin spiroketal, albeit the aglycone of heliquinomycin. ${ }^{7}$ However, their nontraditional spiroketalization method is not easily adapted to the synthesis of $\mathbf{2}$ and $\mathbf{3}$. 8 We therefore thought thermodynamic spiroketalization of compounds $\mathbf{2}$ and $\mathbf{3}$ was an unsound strategy.

We imagined instead that a $p$-naphthoquinone spiroketal could be produced in a single kinetic step amenable to diastereoselective control whereupon the stereochemistry that directed the formation of the spiroketal stereocenter could be erased (Figure 2). The [3+2] oxidative cycloaddition initially observed by Roy and Mandal could be used to test our plan. ${ }^{9}$

pettus@chem.ucsb.edu.

Supporting Information Available: Experimental procedures and key spectral data for all new isolable compounds 5, 7-9, and 1416. This material is available free of charge via the Internet at http://pubs.acs.org. 
The chromanones $\mathbf{4}$ and $\mathbf{5}$ were constructed (Scheme 2). Chromanone $\mathbf{4}$ was prepared in one step from $o$-iodophenol by carbonylation in the presence of norbornadiene, ${ }^{10}$ whereas chromanone 5 was prepared in two steps by dihydroxylation ${ }^{11}$ and subsequent protection as the acetonide. Chromanone $\mathbf{6}$ was commercially available. The carbonyl functionality in these three compounds was individually subjected to methylenation using the Petasis reagent. ${ }^{12}$ After purification, the corresponding exocyclic enol ether was subjected to oxidation by cerium ammonium nitrate in the presence of the 2-hydroxy-1,4-naphthoquinone.

In all the reactions we surveyed, ${ }^{1} \mathrm{H}$ NMR of the crude product mixture reveals a single product. Ranging from 45 to $57 \%$, the isolated yields for 7-9 are modest. To unequivocally establish both the regio- and diastereoselectivity of this transformation, we secured an X-ray structure of 7 (inset, Scheme 1). It indicates that chiral enol ethers undergo reaction from the face of the olefinic $\pi$-system opposite the bulky " $R$ " substituents and on the same side as the neighboring hydrogen atoms. To the best of our knowledge, this transformation is one of only a few diastereoselective oxidative [3 +2$]$ cycloadditions and is perhaps the only example affording a spiroketal in a diastereoselective manner. ${ }^{13}$

The X-ray and ${ }^{1} \mathrm{H}$ NMR data indicate that the corresponding $o$-naphthoquinone product is not present. However, naphthoquinones of this type are base-sensitive as shown by the conversion of 7 with 5\% potassium hydroxide into the naphthoquinone furan reminiscent of $\alpha$-rubromycin (1) (Scheme 4). In a past investigation of $p$-quinones 11 and 13, an equilibration with $o$-quinone counterparts 10 and $\mathbf{1 2}$ was deduced by isolation of the corresponding hydroquinones (Scheme 3). ${ }^{14}$ Therefore, the $p$-naphthoquinone 7 was subjected to reduction. Treatment of 7 with sodium borohydride and in situ methylation with dimethylsulfate afford exclusively the paramethoxynaphthazarin 15 in greater than $90 \%$ yield. None of the corresponding orthomethoxynaphthazarin was evident in the crude product. We conclude that the barrier or groundstate energy difference for $o-, p$-conversion for naphthoquinones 7-9, a rearrangement that we discovered and reported sometime ago, which was subsequently adopted by Kita for the synthesis of $\gamma$-rubromycin ${ }^{8}(\mathbf{3})$ is significantly higher than for the prior quinone counterparts 10-13.

Heating the naphthazarin 15 to $230{ }^{\circ} \mathrm{C}$ in the presence of DEAD causes a retro-cycloaddition to occur, affording the unsaturated $p$-methoxynaphthazarin 16 in $34 \%$ yield (Scheme 4). Further reduction and demethylation affords a hydroquinone intermediate that undergoes immediate oxidation to produce the naphthoquinone spiroketal 9 . The extrusion of cyclopentadiene from 15 validates the notion that chiral substituents within the starting chromanone can be used to direct the formation of the spiroketal stereocenter and can then be erased; therefore, this short strategy is amenable to the enantioselective synthesis of chiral members of the rubromycin family.

With access to several naphthoquinone spiroketal motifs and their naphthazarin counterparts, we began to identify the pertinent pharmacophores in $\beta$-rubromycin. The telomere repeat amplication protocol assay (TRAP) is often employed to examine retained telomerase activity in the presence of an inhibitor. The protocol uses a polymerase chain reaction (PCR) for amplification of DNA extension products to circumvent radioactive labeling and lengthy gel exposure times. The extended oligonucleotide afforded by exposure of a starting telomer to telomerase is then visualized by staining, whereupon the percent activity is determined by densitometry. Comparisons of $\mathrm{IC}_{50}$ 's emerging from different studies should be cautiously interpreted because the telomerase, which is isolated from cancer cells and used in TRAP, is unpurified. Moreover, TRAP only provides an indirect readout of telomerase activity by assuming that the Taq polymerase used for the subsequent amplification remains uninhibited. $15-17$ 
Synthetic compounds 7-9 and 14-16 were analyzed by TRAP. To normalize our findings, we also analyzed BIBR-1532, a well-known telomerase inhibitor. Although reported to have nanomolar potency, ${ }^{18}$ our measured IC $_{50}$ value of $5.62 \pm 0.42 \mu \mathrm{M}$ for BIBR-1532 compared favorably with data obtained by Corey. ${ }^{19}$ Of the compounds tested, only compound $\mathbf{7}$ showed inhibition with an $\mathrm{IC}_{50}$ of approximately $40 \mu \mathrm{M}$ (Figure 3, right curve). However, Hayashi found that $\beta$-rubromycin (2b) also inhibits Taq polymerase, although to a lesser degree than telomerase. This promiscuity requires compound removal to prevent overestimation of potency by inhibition of Taq amplification. Thus, Hayashi extracts $\mathbf{2} \mathbf{b}$ with chloroform before beginning PCR amplification. Because inhibition of the TRAP assay is observed when compound $\mathbf{7}$ is added before and after telomerase elongation, we deduced that that both Taq polymerase and telomerase are inhibited. Therefore, with commercial $\beta$-rubromycin (2b) serving as a standard, the respective inhibitors were removed by spin column separation before PCR amplification. In our hands, the spin column method of separation is less time consuming and leads to improved recovery, precision, and accuracy over chloroform extraction. Our results show that $\beta$-rubromycin (2b) inhibits telomerase as expected and validates our modified procedure. Compound 7 now afforded an $\mathrm{IC}_{50}$ value at a slightly higher concentration $(60 \mu \mathrm{M}$ for 50\% activity; Figure 3, left curve).

Although compound $\mathbf{7}$ contains the spiroketal moiety suggested as the privileged pharmacophore in the rubromycin family, some structurally similar compounds in our study $(\mathbf{8 , 9}, \mathbf{1 5}$, and 16) did not show any inhibition in the standard TRAP assay at concentrations of up to $400 \mu \mathrm{M}$. This surprising finding could indicate that structural components other than the spiroketal alone contribute to inhibition or that additional hydrophobicity in the pyranoid ring is desirable for inhibition. As might be expected, removal of the spiroketal moiety in $\mathbf{7}$ (compound 14) results in the loss of all activity. This effect is consistent with Hayashi's previous hypothesis that the spiroketal serves as the central pharmacophore and the difference in activity between $\beta$-rubromycin, which contains a spiroketal, and $\alpha$-rubromycin, which does not. Remarkably, when the naphthoquinone in $\mathbf{7}$ was reduced and methylated to form the naphthazarin spiroketal $\mathbf{1 5}$, all activity was again lost.

These observations suggest that the spiroketal, the naphthoquinone, and the norbornene synergistically cooperate with regard to efficacy. However, because the norbornene in $\mathbf{7}$ is absent from both $\beta$-rubromycin (2b) and the inactive analogue $\mathbf{9}$, inhibition by compound $\mathbf{7}$ may occur through a different mechanism. However, additivity studies with $\mathbf{7}$ and $\mathbf{2 b}$ to elucidate the similar or dissimilar modes of action proved inconclusive.

In summary, our synthetic strategy lays the groundwork for rapid enantioselective entry into the spiroketal motif of chiral rubromycin skeletons by introducing a chiral substituent in proximity to the spiroketal center. After removal of the chiral auxiliary via retro-cycloaddition, the desired spiroketal can be constructed. Furthermore, our studies indicate that when tested under identical conditions $\beta$-rubromycin (2b) is more potent than BIBR-1532, which has previously been reported as a nanomolar inhibitor. Last, our convergent strategy is well positioned to enable a careful and critical examination of the biological effects of each functional group, which is important for $\beta$-rubromycin binding and selectivity.

Acknowledgment

This research had been funded in the past by UC-CRCC and by the NSF, the latter an early Career Award (0135031) to T.R.R.P.

\section{References}

1. Brasholz M, Sörgel S, Azap C, Reissig H-U. Eur. J. Org. Chem 2007:3801. 
2. (a) Brockmann H, Lenk W, Schwantje G, Zeeck A. Tetrahedron Lett 1966:3525. [PubMed: 5955233]

(b) Brockmann H, Lenk W, Schwantje G, Zeeck A. Chem. Ber 1969;102:126. [PubMed: 5764292]

(c) Brockmann H, Zeeck A. Chem. Ber 1970;103:1709. [PubMed: 5447178]

3. Puder CL, Loya S, Hizi A, Zeeck A. Eur. J. Org. Chem 2000:729.

4. Bringmann G, Kraus J, Schmitt U, Puder C, Zeeck A. Eur. J. Org. Chem 2000:2729.

5. (a) Tsang KY, Brimble MA, Bremner JB. Org. Lett 2003;5:4425. [PubMed: 14602016] (b) Tsang KY, Brimble MA. Tetrahedron 2007;63:6015. (c) Thrash TP, Welton TD, Behar V. Tetrahedron Lett 2000;41:29. (d) Stevens JL, Welton TD, Deville JP, Behar V. Tetrahedron Lett 2003;44:8901. (e) Brasholtz M, Reissig H-U. Synlett 2004;15:2736. (f) Sörgel S, Azap C, Reissig H. Eur. J. Org. Chem 2006:4405. (g) Waters SP, Kozlowski MC. Tetrahedron Lett 2001;42:3567. (h) Xie X, Kozlowski MC. Org. Lett 2001;3:2661. [PubMed: 11506603] (i) Waters SP, Fennie MW, Kozlowski MC. Org. Lett 2006;8:3423. (j) Waters SP, Fennie MW, Kozlowski MC. Tetrahedron Lett 2006;47:5409.Waters, SP. Ph.D. Thesis. PA. U.S.A.: Univ. of Pennsylvania; 2004. (1) Sörgel S, Azap C, Reissig H. Org. Lett 2006;8:4875. [PubMed: 17020325] (m) Brashoz M, Sörgel S, Azap C, Reissig H. Eur. J. Org. Chem 2007:3801.

6. (a) Capecchi T, de Koning CB, Michael JP. Tetrahedron Lett 1998;39:5429. (b) Capecchi T, de Koning CB, Michael JP. J. Chem. Soc., Perkins Trans. 1 2000:2681.

7. Danishefsky arrived at the racemic aglycone of heliquinonmycin after 26 steps. Heliquinomycin, like griserhodin C, contains three stereocenters. (a) Qin D, Ren RX, Siu T, Zheng C, Danishefsky SJ. Angew. Chem., Int. Ed 2001;40:4709. (b) Siu T, Qin D, Danishefsky SJ. Angew. Chem., Int. Ed 2001;40:4713.

8. Akai S, Kakiguchi K, Nakamura Y, Kuriwaki I, Dohi T, Harada S, Kubo O, Morita N, Kita Y. Angew. Chem., Int. Ed 2007;46:7458.

9. Roy SC, Mandal PK. Tetrahedron 1996;52:12495.

10. (a) An Z-W, Catellani M, Chiusoli P. J. Organomet. Chem 1989;371:C51. (b) An Z-W, Catellani M, Chiusoli P, Paolo G. Gazz. Chim. Ital 1990;120:383. (c) Moinet C, Fiaud J-C. Synlett 1997;97

11. Plietker B, Niggemann M. J. Org. Chem 2005;70:2402. [PubMed: 15760243]

12. Petasis NA, Bzowej EI. J. Am. Chem. Soc 1990;112:6392.

13. Schmidt B, Wildemann H. Eur. J. Org. Chem 2000:3145.

14. Lindsey CC, Wu K-L, Pettus TRR. Org. Lett 2006;8:2365. [PubMed: 16706527]

15. Kim NW, Piatyszek MA, Prowse KR, Harley CB, West MD, Ho PL, Coviello GM, Wright WE, Weinrich SL, Shay JW. Science 1994;266:2011. [PubMed: 7605428]

16. (a) Piatyszek MA, Kim SL, Weinrich SL. Methods Cell Sci 1995;17:1. (b) Pascolo E, Wenz C, Lingner J, Hauel N, Priepke H, Kauffmann I, Garin-Chesa P, Rettig WJ, Damm K, Schnapp A. J. Biol. Chem 2002;277:15566. [PubMed: 11854300]

17. Kazmer S, Pan KM, Vassilev L. J. Biochem. Biophys. Methods 1999;40:113-117. [PubMed: 10487165]

18. Damn K, Hermmann U, Garin P, Hauel N, Kauffmann I, Priepke H, Niestrol C, Daiber C, Enenkel B, Guillard B, Lauritsch I, Müler E, Pascolo E, Sauter G, Pantic M, Martens UM, Wenz C, Ligner J, Kraut N, Rettig WJ, Schnapp A. EMBO J 2001;20:6958. [PubMed: 11742973]

19. Bamra DK, Elayadi A, Falck JR, Corey DR. Bioorg. Med. Chem. Lett 2003;13:1333. [PubMed: 12657276] 
<smiles>COc1cc(OC)c2c(c1O)C(=O)c1oc(CCc3cc4cc(C(=O)O)oc(=O)c4c(O)c3O)cc1C(=O)[C@H](C(C)CO)O2</smiles><smiles>COc1cc(OC)c2c(c1O)C(=O)C(=O)C1=C2O[C@@]2(CCc3cc4cc(C(OC)OC)oc(=O)c4c(O)c3O2)C1</smiles>

$\beta$-rubromycin (2a) as proposed in 1966<smiles></smiles>

(+)- $\beta$-rubromycin (2b) as revised in 2000<smiles>COC1=CC(=O)c2c(O)c3c(c(O)c2C1=O)O[C@]1(CCc2cc4cc(C(=O)O)oc(=O)c4c(O)c2O1)O3</smiles>

Figure 1.

Rubromycin family. 


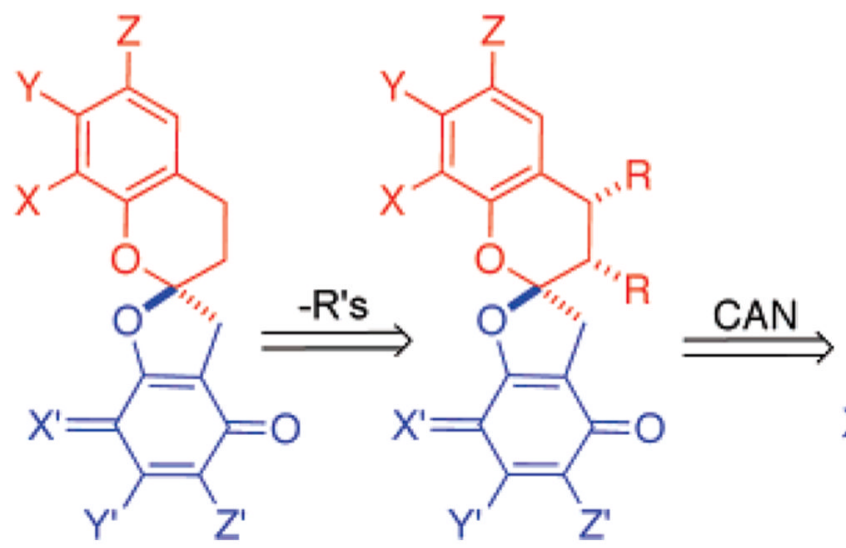<smiles>[X]c1cc2c(c([Y])c1[Y])OC(=C)[C@H]([R])[C@@H]2[R]</smiles>

Figure 2.

Retrosynthetic strategy amenable to stereocontrol. 

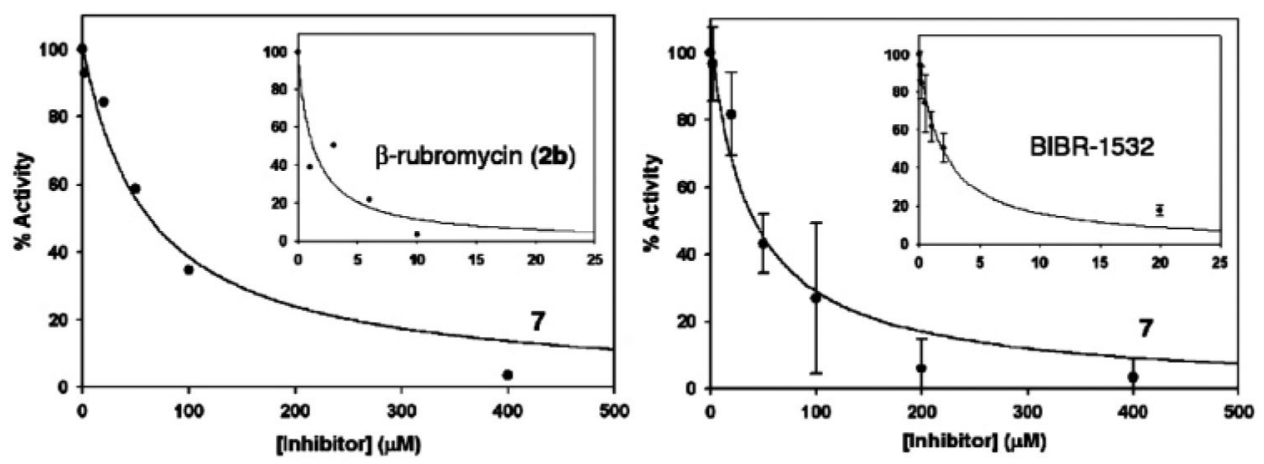

Figure 3.

TRAP inhibition curves. Left curves, show \% telomerase activity with spin column separation of inhibitor before PCR amplification for $\beta$-rubromycin (2b) and compound 7. Right curves, show \% activity for BIBR-1532 and 7 without compound separation prior to PCR amplification. 


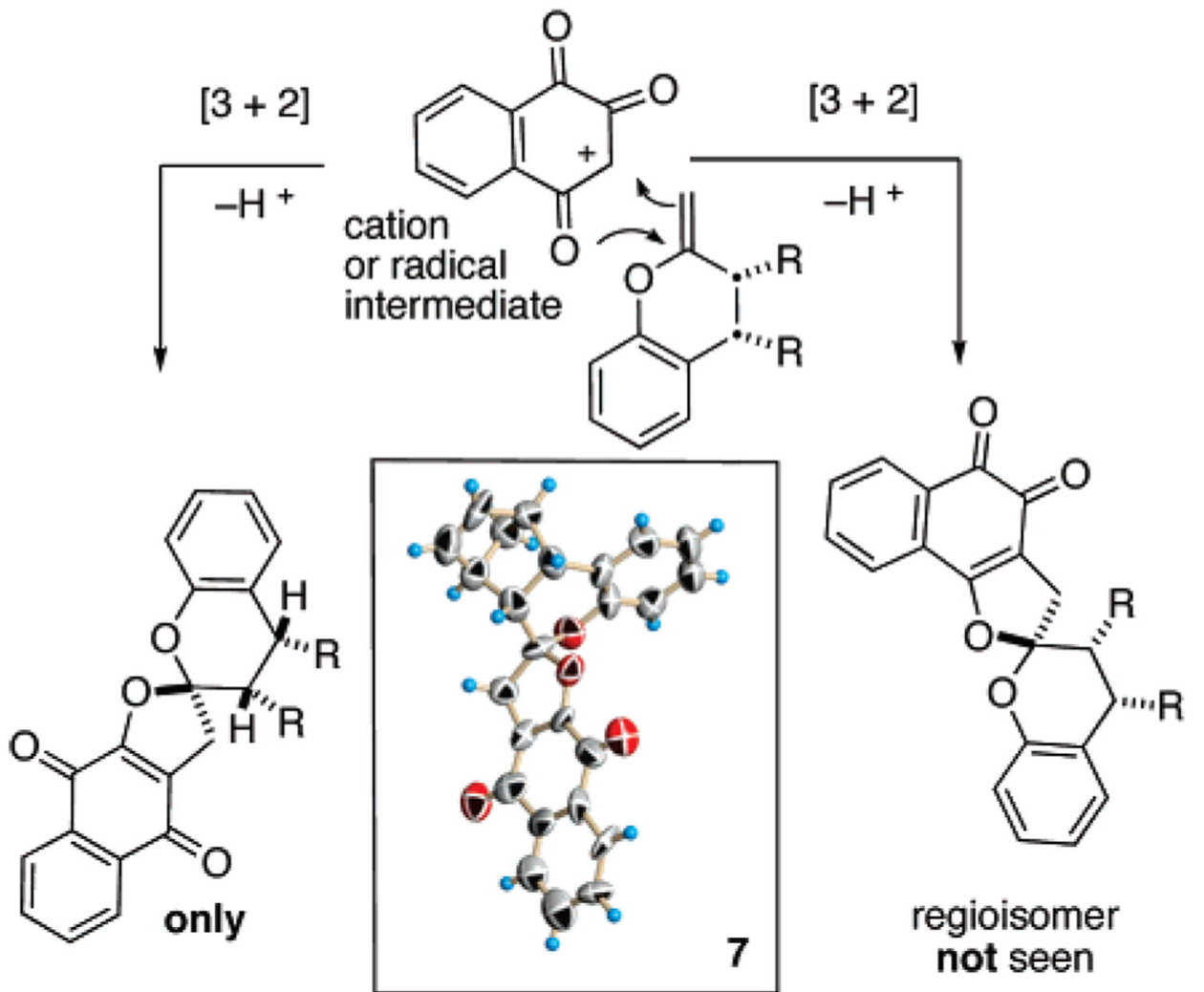

Scheme 1.

Regioselective and Diastereoselective Concerns 
<smiles>O=C1Oc2ccccc2[C@@H]2[C@@H]1[C@H]1C=C[C@H]2C1</smiles><smiles>CC1(C)O[C@@H]2C(=O)Oc3ccccc3[C@H]2O1</smiles><smiles>O=C1CCc2ccccc2O1</smiles>
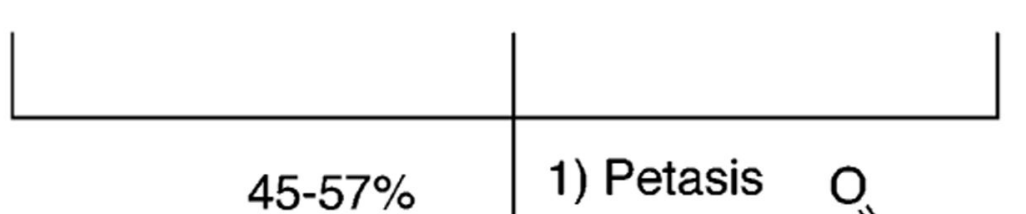

1) Petasis $O$ over 2 steps

2) $\mathrm{CAN}$,<smiles>O=C1C=C(O)C(=O)c2ccccc21</smiles>
$\mathrm{NaHCO}_{3}$, THF

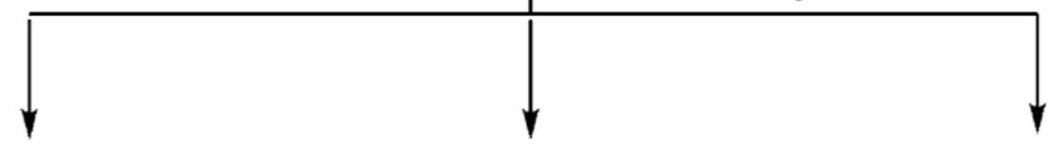<smiles>O=C1C2=C(O[C@]3(C2)Oc2ccccc2[C@H]2[C@H]4C=C[C@@H](C4)[C@H]23)C(=O)c2ccccc21</smiles>

\section{7}<smiles>CC1(C)O[C@H]2c3ccccc3O[C@]3(CC4=C(O3)C(=O)c3ccccc3C4=O)[C@H]2O1</smiles>

8 one diastereomer one diastereomer<smiles>O=C1C2=C(O[C@@]3(CCc4ccccc4O3)C2)C(=O)c2ccccc21</smiles>

9

Scheme 2.

Some Spiroketals Available from Chromanone Methylenation and Subsequent Oxidative [3+ 2] Cycloaddition 

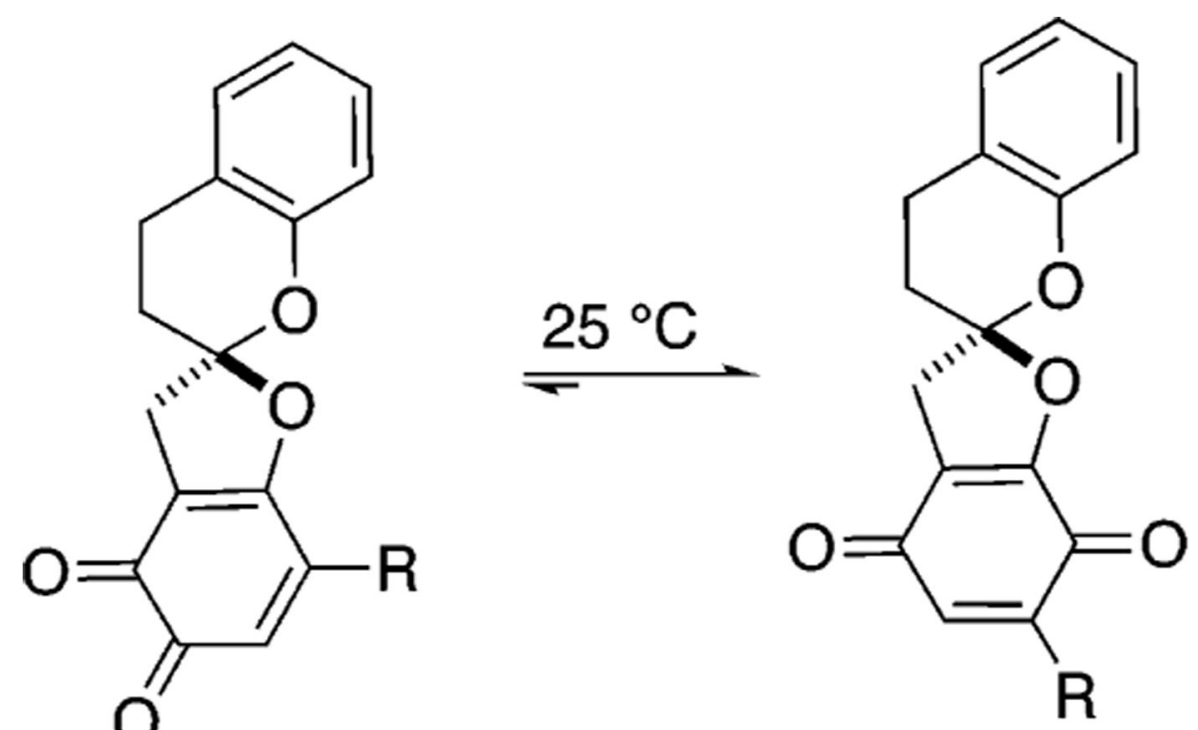

10: $\mathrm{R}=\mathrm{H}$

11: $\mathrm{R}=\mathrm{H}$

12: $\mathrm{R}=\mathrm{Cl}$

13: $\mathrm{R}=\mathrm{Cl}$

Scheme 3.

Equilibrium Encountered in Other $o$ - and $p$-Quinones 

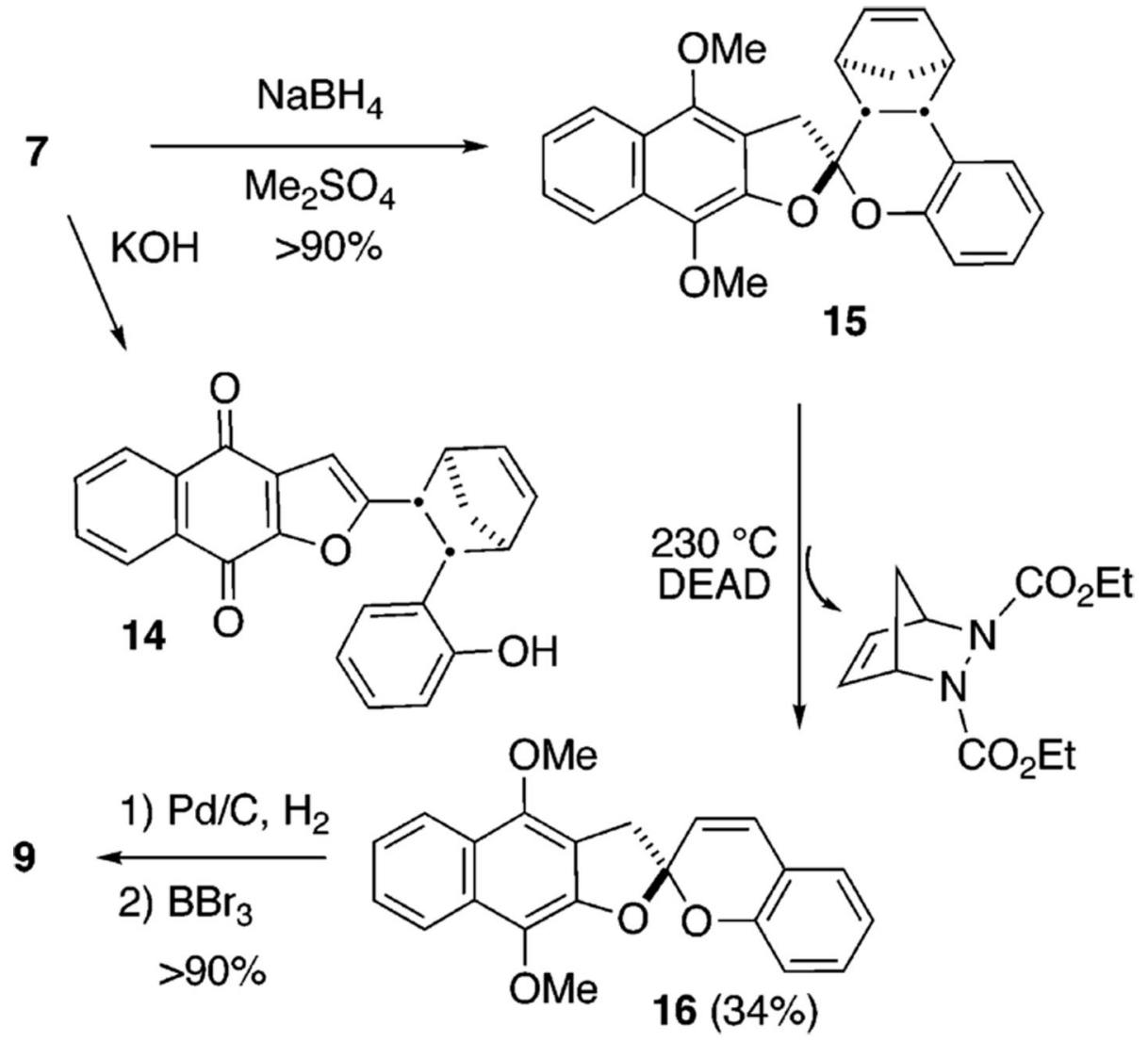

Scheme 4.

Some Reactions of the Norbornene Derivatives 